\title{
Twin pregnancy with complete hydatidiform mole and a coexisting viable fetus
}

\author{
Gihan $\mathrm{MC}^{1}$, Rajapaksha $\mathrm{RNG}^{2}$, Rannulu $\mathrm{P}^{3}$
}

\section{INTRODUCTION}

A twin pregnancy with complete hydatidiform molar and coexisting live fetus is a very rare Obstetric problem. It is estimated that that the incidence is 1 in $20,000-100,000$ pregnancies $^{1}$. It carries complications of complete molar pregnancy such as persistent trophoblastic disease, early onset pre-eclampsia and thyrotoxicosis. Diagnosis can be made by the prenatal ultrasound examination. Management is a challenge as the clinician needs to decide whether to continue or terminate the pregnancy. If patient decides to continue with the pregnancy, she should be counseled for possible increased risk of perinatal morbidity and sequelae of Gestational Trophoblastic Neoplasia (GTN) ${ }^{2}$.

\section{CASE REPORT}

A 37 years old multigravida who had a history of molar pregnancy in her first gestation was presented in her fourth pregnancy during first trimester. She had excessive vomiting and continuous mild per-vaginal bleeding during first trimester and routine first trimester ultrasound scan revealed a dichorionic pregnancy with one complete molar and one healthy fetus (Figure 1). Subsequent laboratory investigations showed free Thyroxin $\left(\mathrm{FT}_{4}\right) 8.16 \mathrm{ng} / \mathrm{dL}(0.7-1.48)$, Thyroid Stimulating Hormone (TSH)

\footnotetext{
1 Department of Obstetrics and Gynecology, Faculty of Medicine, University of Peradeniya.

2 Obstetrics and Gynaecology unit, North Colombo Teaching Hospital, Ragama.

3 Obstetrics and Gynaecology unit, Base Hospital, Marawila, Sri Lanka.
}

\section{Correspondence: Dr. M C Gihan}

E-mail: champikagihan@yahoo.com

Competing interests: None
$<0.004 \mu \mathrm{IU} / \mathrm{ml}(0.35$ - 4.94), Alanine Transaminase (ALT) $101 \mathrm{U} / \mathrm{L}(30$ 65), Aspartate Transaminase (AST) 64 U/L (15 - 37), serum Sodium 133 $\mathrm{mmol} / \mathrm{L}(137$ - 145), serum Potassium $4.1 \mathrm{mmol} / \mathrm{L}$ (3.5 - 5.1), serum Chloride $96 \mathrm{mmol} / \mathrm{L}(98$ - 105), serum $\beta$ human chorionic gonadotropin (hCG) > 225,000 mIU/ml.

She was clinically hyperthyroid due to excessive serum hCG which has a TSH action. It was managed with an antithyroid drug (Carbimazole). Enteral and parenteral antiemetics were used to manage excessive vomiting. Despite of counseling of adverse outcomes, patient opted to continue the pregnancy. Prenatal invasive testing for fetal karyotype was not done and maternal parameters were monitored carefully.

At the 16 weeks of gestation patient admitted with severe pervaginal bleeding and she was hemodynamically unstable. On examination she was severely pale, and having tachycardia and hypotension. Her symphysio-fundal height was compatible with 24 weeks of gestation. Ultrasound scan confirmed the previous findings.

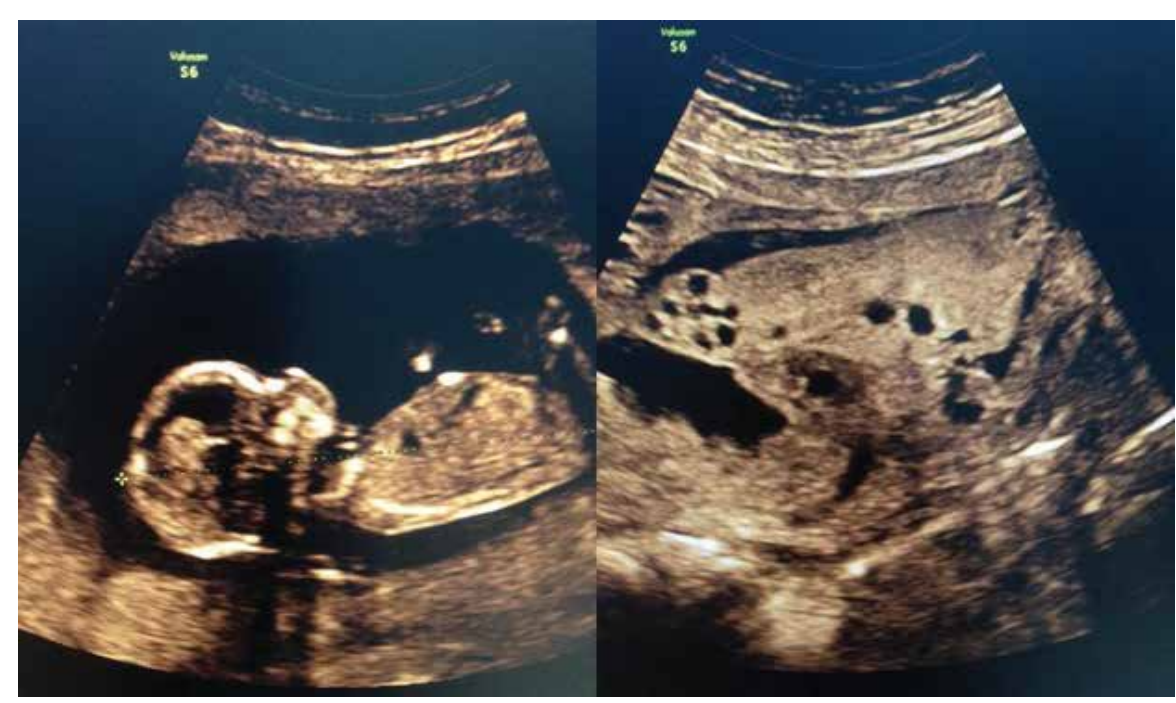

Figure 1: Ultrasound appearance of the healthy fetus and the complete mole of the dichorionic twin pregnancy
As mother had intractable bleeding with unfavorable. An emergency hysterotomy cervix, termination of pregnancy was considered. was performed. A large amount of molar tissues and the live nonviable fetus were evacuated and sent for histo-pathological assessment. There was a significant bleeding from the endometrial lining and intra-operative tranexamic acid was given. Compression sutures (B Lynch sutures) were applied due to persistent bleeding in spite of medical management. Post-operative intensive care was given for a one day and patient recovered fully. Histopathology revealed complete hydatidiform molar pregnancy with a normal fetus.

\section{DISCUSSION}

GTN is a neoplasm of the placenta. Hydatidiform molar pregnancy is a component of the spectrum of GTN. Hydatidiform molar can occur in singleton as well as in multiple gestations. Coexistence of a molar pregnancy and a normal fetus is a rare occurrence. This broad entity can be 
Table 1: Classification of $\mathrm{H}$ mole in a twin gestation

1. Twin gestation in which one twin is a diploid fetus with a normal placenta ( 46 chromosomes, 23 maternal and 23 paternal) and the other twin is a complete hydatidiform mole (46 chromosomes of paternal origin) with no fetus.

2. Twin gestation in which one twin is a diploid fetus with normal placenta (46 chromosomes, 23 maternal and 23 paternal) and the other twin is a triploid fetus with partial hydatidiform mole placenta (69 chromosomes, 23 maternal and 46 paternal).

3. Singleton gestation consisting of a triploid fetus with partial hydatidiform mole placenta (69 chromosomes, 23 maternal and 46 paternal) ${ }^{3}$.

4. Hypertrophic placental tissues.

classified into four types (table 1).

Prenatal invasive testing for fetal karyotype should be considered if the diagnosis is unclear ${ }^{2}$. Unlike partial hydatidiform mole which is commonly associated with multiple fetal abnormalities, the second scenario (like in our case report) is not associated with fetal anomalies in the coexisting live fetus.

Early diagnosis of hydatidiform mole with twin live fetus is feasible at present with the availability and recent advances in ultrasound ${ }^{4}$. Management options include conservative management with careful monitoring of maternal parameters and immediate termination of the pregnancy. Development of life threatening complications like pre-eclampsia, severe maternal hemorrhage and persistent Gestational Trophoblastic Disease (pGTD) are possible consequences of conservative management. It is estimated that only $25 \%$ of such cases will progress beyond 20 weeks of gestation and majority will result in spontaneous abortion before that with conservative management ${ }^{5}$. Furthermore, there is $40 \%$ chance of live birth without significantly increasing the chance of pGTD $^{6}$. Immediate termination of the pregnancy is an option as it prevents PGTD and maternal medical problems ${ }^{7}$. So the management of a pregnancy with complete hydatidiform mole and a coexisting viable fetus depends on the clinical scenario. Conservative management is justifiable if fetal karyotype is normal and maternal complications can be controlled $^{8}$.

\section{REFERENCES}

1. Malhotra N, Deka D, Takkar D, Kochar S, Goel S, Sharma MC. Hydati-form mole with coexisting live fetus in dichorionic twin gestation. Eur J Obstet Gynecol Reprod Biol.2001;94:301-303.

2. Royal College of Obstetricians and Gynecologists. Green-top
Guideline. No. 38. February 2010.

3. Sheri AEMS, Mohammed KA, Ahmed YAB, Abu-bakr AA, Mostafa MK, Nehal AEM. Twin pregnancy with complete hydatidiform mole and coexisting fetus following ovulation induction with a non-prescribed clom-iphene citrate regimen: a case report. Journal of Medical Case Reports. 2012;6:95-99.

4. Jauniaux E. Ultrasound diagnosis and follow-up of Gestational Tropho-blastic Disease. Ultrasound. Obstet. Gynecol., 1998;11:367-377.

5. Bristow RE, Shumway JB, Khouzami AN, Witter FR. Complete hydatid-iform mole and surviving coexisting twin. Obstet Gynecol Surv 1996;51:7059

6. Sebire NJ, Foskett M, Paradinas FJ, Fisher RA, Francis RJ, Short D, Newlands ES, Seckl MJ. Outcome of twin pregnancies with complete hydatidiform mole and healthy co-twin. Lancet.2002;359:2165-2166.

7. Block M F, Merrill J A. Hydatidiform mole with coexisting fetus. Obstet. Gynecol. 1982;60:129-134.

8. Matsui $H$, Sekiya $S$, Hando $T$, Wake N, Tomoda Y.Hydatidiform mole coex-istent with a twin live fetus: a national collaborative study in Japan. Hum Re-prod. 2000;15:608-611. 